\title{
Successful experience with simultaneous lung volume reduction and cardiac procedures
}

\author{
Joseph B. Shrager, MD, Benjamin W. Kozyak, John R. Roberts, MD, Joseph E. Bavaria, MD, \\ Joseph S. Friedberg, MD, Larry R. Kaiser, MD, and Bruce R. Rosengard, MD, Philadelphia, Pa
}

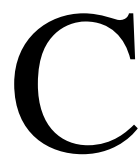

oronary artery disease (CAD) is prevalent in candidates for lung volume reduction surgery (LVRS), ${ }^{1}$ and significant valve dysfunction may also coexist with severe emphysema. The National Emphysema Treatment Trial (NETT) excludes patients with a variety of cardiovascular risk factors from undergoing LVRS, ${ }^{2}$ as do many surgeons who perform the procedure outside of the trial. Few have performed LVRS in those patients with severe CAD that cannot be managed percutaneously. Thus, although the literature on combining cardiac procedures and pulmonary resections for cancer is extensive, we have identified only 4 published cases $^{3-5}$ from 3 different groups using diverse operative strategies combining cardiac procedures and LVRS. We report our series of 4 combined, simultaneous cardiac/LVRS procedures to aid in determining whether this is an appropriate approach in selected patients and, if so, to help select the ideal operative strategy.

\section{Patients and Results}

Four patients underwent combined cardiac/bilateral LVRS procedures via median sternotomy between May 1997 and May 2000. These 4 patients represent all those in whom there was a preoperative plan to perform a combined procedure. That is, no planned combined procedures were aborted because of intraoperative events. Three patients had coronary artery bypass grafting (CABG) in combination with LVRS, and 1 patient underwent aortic valve replacement (AVR) with LVRS. Each CABG/LVRS included a left internal thoracic artery graft; there were 1 single vessel CABG (for left anterior descending disease spanning a large diagonal orifice thought not amenable to angioplasty) and 2 double vessel CABGs. A bioprosthetic valve was used for the AVR/LVRS. All patients were excellent candidates for LVRS on the basis of hyperexpansion (Table 1), disease distribution (mean upper third lung perfu-

From the Division of Cardiothoracic Surgery, University of Pennsylvania School of Medicine, Philadelphia, Pa.

Received for publication Jan 5, 2001; accepted for publication Jan 9, 2001.

Address for reprints: Joseph B. Shrager, MD, 6 Silverstein, Hospital of the University of Pennsylvania, 3400 Spruce St, Philadelphia, PA 19104 (E-mail: jshrag@mail.med.upenn.edu).

J Thorac Cardiovasc Surg 2001;122:196-7

Copyright $\odot 2001$ by The American Association for Thoracic Surgery

$0022-5223 / 2001 \$ 35.00+0 \quad \mathbf{1 2 / 5 4 / 1 1 4 0 9 4}$

doi:10.1067/mtc.2001.114094 sion $6.1 \%$ ), and the absence of pulmonary factors believed by the surgeons to increase operative risk (eg, absence of marked $\mathrm{PCO}_{2}$ elevation or dramatically low diffusing capacity of the lung for carbon monoxide). Similarly, all patients had normal ejection fractions, and the planned cardiac procedures were deemed relatively straightforward. Mean age was 64.8 years.

The cardiac procedures were each performed with cardiopulmonary bypass (CPB) before LVRS. Lung volume reduction was performed while still on $\mathrm{CPB}$ in 1 patient and after heparin reversal and termination of CPB in 3 patients. Mean operative time was 207 minutes. One patient was extubated in the operating room and the others were extubated a mean of 14 hours postoperatively. There were no major complications and 5 minor complications including atrial fibrillation $(\mathrm{n}=1)$, superficial wound infection $(n=1)$, and air leak greater than 7 days $(n=3)$. Mean length of stay was 9.8 days. Three patients were discharged with Heimlich valves; mean time to removal of all chest tubes was 11.5 days. All patients are alive and well a mean of 22.8 months after the procedure. Postoperative pulmonary function tests have been obtained in 3 patients. Postoperative improvements in pulmonary function are similar to those reported after isolated LVRS procedures (Table 1).

\section{Discussion}

Untreated, significant CAD or valvular disease increases the risk of morbidity and mortality associated with pulmonary surgery. These increased risks are likely to be even more important after an operation such as LVRS that severely stresses patients who begin with marginally compensated cardiopulmonary function. Although many candidates for LVRS have CAD that may be amenable to correction by percutaneous intervention, some have multivessel disease, single vessel disease not appropriate for angioplasty, or valvular disease that requires operative repair. Options in these patients include foregoing LVRS, performing LVRS and the cardiac procedure under separate anesthetics, or combining the 2 procedures in a single operation, as we have done in the 4 cases reported here.

If such a simultaneous procedure can be performed with the same morbidity, mortality, and functional outcome as the procedures performed separately, then there are several reasons to favor the simultaneous procedure. The most obvious advantages are the improved patient convenience and the almost certainly reduced costs associated with combining the operations. More important, however, is the avoidance of difficulties that may be associated with performing the operations singly. For example, a redo sternotomy to perform the second procedure increases risk unnecessarily, and even if one is performing a thoracoscopic LVRS remotely after sternotomy, there are likely to be problems with 
TABLE 1. Preoperative and postoperative testing

\begin{tabular}{lccccc}
\hline & FEV $_{\mathbf{1}}$ & RV & 6MWT (ft) & $\mathbf{0}_{\mathbf{2}}$ & RA ABG \\
\hline Preop & $0.91 \mathrm{~L}(27 \%)$ & $5.46 \mathrm{~L}(240 \%)$ & 1304 & $1 \mathrm{~L}$ & $7.41 / 43 / 69 / 27$ \\
Postop & $1.14 \mathrm{~L}(35 \%)$ & $3.03 \mathrm{~L}(134 \%)$ & 1441 & $0.33 \mathrm{~L}$ & - \\
$\%$ Change & +55 & -44 & +14 & -66 & - \\
\hline
\end{tabular}

Preoperative studies include all 4 patients; postoperative studies and percent changes include 3 of the 4 patients. Postoperative studies were performed 3 to 12 months after the operations. All values are means. $F E V{ }_{1}$, Forced expiratory volume in 1 second; $R V$, residual volume; $6 M W T, 6$-minute walking test; $O_{2}$, oxygen; $R A$, room air; $A B G$, arterial blood gases.

adhesions and resulting air leaks. Finally, some patients who are denied a cardiac operation because of their poor pulmonary function may, however, be candidates for a combined procedure.

We demonstrate by the 4 cases reported herein that simultaneous performance of LVRS and cardiac procedures using CPB can be done safely and with improvements in pulmonary function similar to those reported after isolated LVRS procedures. Although others have reported performing the LVRS portion before $\mathrm{CPB}^{4}$ or while the patient is still anticoagulated on $\mathrm{CPB},{ }^{3}$ we favor performing the cardiac procedure first, with heparin reversal and discontinuation of CPB before LVRS. This technique, which we used in 3 of our 4 patients, does not preclude creating a left internal thoracic artery graft. Furthermore, this approach minimizes the risk of pulmonary contusion and allows the surgeon to see the lung in the incompletely deflated state that highlights gas-retaining target areas.

\section{References}

1. Thurnheer R, Mutwyler J, Stammberger U, Block KE, Zollinger A, Weder, W, et al. Coronary artery disease in patients undergoing lung volume reduction surgery for emphysema. Chest. 1997;112:122-8.

2. The National Emphysema Treatment Trial Research Group. Rationale and design of the National Emphysema Treatment Trial (NETT): a prospective randomized trial of lung volume reduction surgery. $J$ Thorac Cardiovasc Surg. 1999;118:518-28.

3. Schmid RA, Stammberger U, Hillinger S, Vogt PR, Amman FW, Russi $\mathrm{EW}$, et al. Lung volume reduction surgery combined with cardiac interventions. Eur J Cardiothorac Surg. 1999;15:585-91.

4. Whyte RI, Bria W, Martinez FJ, Lewis P, Bolling SF. Combined lung volume reduction and mitral valve reconstruction. Ann Thorac Surg. 1998;66:1414-6.

5. Oto O, Hazan E, Silistreli E, Erturk M, Catalyurek H, Acikel U. Lungvolume reduction in parallel with coronary heart surgery: a case report. J Int Med Res. 1998;26:266-9. 